\title{
Study on thermodynamic properties of binary mixtures of diethyl carbonate with benzonitrile, benzaldehyde at different temperatures
}

\author{
B. Sudhamsa ${ }^{1}$, M. Sarath Babu ${ }^{1}$, K. Narendra ${ }^{2, *}$ \\ ${ }^{1}$ Department of Chemistry, MIC College of Technology, Kanchikacharla, India \\ ${ }^{2}$ Department of Physics, V.R. Siddhartha Engineering College (Autonomous), Vijayawada, India \\ *Phone: +9198850 38074 \\ *E-mail address: drkollanarendra@gmail.com
}

\begin{abstract}
The speed of sound and density in binary liquid mixture of diethyl carbonate + benzonitrile, + benzaldehyde have been determined at temperatures 298.15 , 308.15 and $318.15 \mathrm{~K}$ over the whole composition range. The data have been utilized to estimate the excess adiabatic compressibility $\left(\beta^{\mathrm{E}}\right)$, excess intermolecular free length $\left(\mathrm{L}_{\mathrm{f}}^{\mathrm{E}}\right)$, excess speed of sound $\left(\mathrm{u}^{\mathrm{E}}\right)$ at the above temperatures. The excess values have been found to be useful in estimating the strength of the interactions in the liquid mixtures.
\end{abstract}

Keywords: Binary mixtures; Excess adiabatic compressibility; Excess free length; Excess speed of sound

\section{INTRODUCTION}

Due to their unusual behavior, binary liquid mixtures have attracted considerable attention in different fields. In chemical process industries, materials are normally handled in fluid form and as a consequence, the physical, chemical, and transport properties of fluids assume importance [1-4]. Thus data on some of the properties associated with the liquids and liquid mixtures like speed of sound, density, excess adiabatic compressibility, excess free length and excess speed of sound find extensive applications in chemical industry and engineering design $[5,6]$. Diethyl carbonate (DEC) is a solvent of both extraction and reaction used in many industries such as agrochemicals, pharmaceuticals and hydrocarbon refinery. It can make dyeing uniformity and increase fading against sunshine. DEC was also proposed as lubricant of the new refrigerant, hydro fluorocarbon and as paint remover in the paint industry.

Benzonitrile and benzaldehyde are important liquids which find variety of applications such as solvent for lacquers, oils and resins. Several researchers [7,8] studied the molecular interactions in binary liquid mixtures containing diethyl carbonate by measuring the values of density and speed of sound. As a part of the experimental investigation of the excess thermodynamic properties of industrially important liquids like diethyl carbonate, here we report the densities, speeds of sound, excess adiabatic compressibility $\left(\beta^{\mathrm{E}}\right)$, excess 
intermolecular free length $\left(\mathrm{L}_{\mathrm{f}}^{\mathrm{E}}\right)$ and excess speed of sound $\left(\mathrm{u}^{\mathrm{E}}\right)$ for binary mixtures of the above mentioned systems at temperatures $(298.15,308.15$ and 318.15$) \mathrm{K}$ over the entire composition range.

\section{MATERIALS AND METHODS}

All the chemicals used in this study were purchased from Sigma Aldrich Chemicals Company. According to the manufacturer, the purities of these compounds were $>99 \%$. The purity of the samples was checked by comparing the observed values of densities, speeds of sound and refractive indices with those reported in literature and were used as such without further purification.

Anton Paar DSA 5000 density and sound analyzer provided with two Pt 100 platinum thermometer was used for measuring the densities and speeds of sound of pure liquids and liquid mixtures. The density is extremely sensitive to temperature, so the apparatus was controlled to $\pm 0.001 \mathrm{~K}$ by a built-in solid state thermostat. The stated accuracy in density and speed of sound are $5 \times 10^{-3} \mathrm{kgm}^{-3}$ and $0.5 \mathrm{~m} / \mathrm{s}$ respectively.

The binary liquid mixtures were prepared by mixing known masses of pure liquids in airtight-stoppered bottles to minimize evaporation losses. The weighings were done with an electronic balance with a precision of $\pm 0.01 \mathrm{mg}$.

\section{THEORY}

The adiabatic compressibility has been determined by using the experimentally measured speed of sound $(u)$ and density $(\rho)$ by the following formula

$$
\beta_{\mathrm{ad}}=1 / \rho \mathrm{u}^{2}
$$

Inter Molecular free length $\left(\mathrm{L}_{\mathrm{f}}\right)$ was calculated by using the relation

$$
\mathrm{L}_{\mathrm{f}}=\mathrm{K}\left(\beta_{\mathrm{ad}}\right)^{1 / 2}
$$

where $\mathrm{K}$ is temperature dependent Jacobson's constant.

The excess properties such as $\beta^{\mathrm{E}}, \mathrm{L}_{\mathrm{f}}^{\mathrm{E}}$ and $\mathrm{u}^{\mathrm{E}}$ have been calculated using the equation

$$
\mathrm{Y}^{\mathrm{E}}=\mathrm{Y}_{\text {mix }}-\left[\mathrm{x}_{1} \mathrm{Y}_{1}+\mathrm{x}_{2} \mathrm{Y}_{2}\right]
$$

where $\mathrm{Y}^{\mathrm{E}}$ is $\beta^{\mathrm{E}}$ or $\mathrm{L}_{\mathrm{f}}^{\mathrm{E}}$ or $\mathrm{u}^{\mathrm{E}}$, and $\mathrm{x}$ represents mole fraction of the component and subscripts 1 and 2 stand for the components 1 and 2 .

The excess thermodynamic functions are sensitively dependent not only on difference in Intermolecular forces but different in the size of molecules. Density and speed of sound measurements are used to calculate the adiabatic compressibility and intermolecular free length of liquids and the effects of the change in composition and temperature on the excess adiabatic compressibility, excess intermolecular free length and excess speed of sound of the binary mixture have been evaluated by several researchers [9,10,13-15]. The study of excess values provides important information on molecular forces existing in the binary liquid mixtures. Depending upon the nature of the liquids whether they are polar or non polar, the 
signs and magnitudes of these excess values can throw light on strength of interactions. The present paper encloses the study of various excess parameters as follows.

\section{RESULTS AND DISCUSSION}

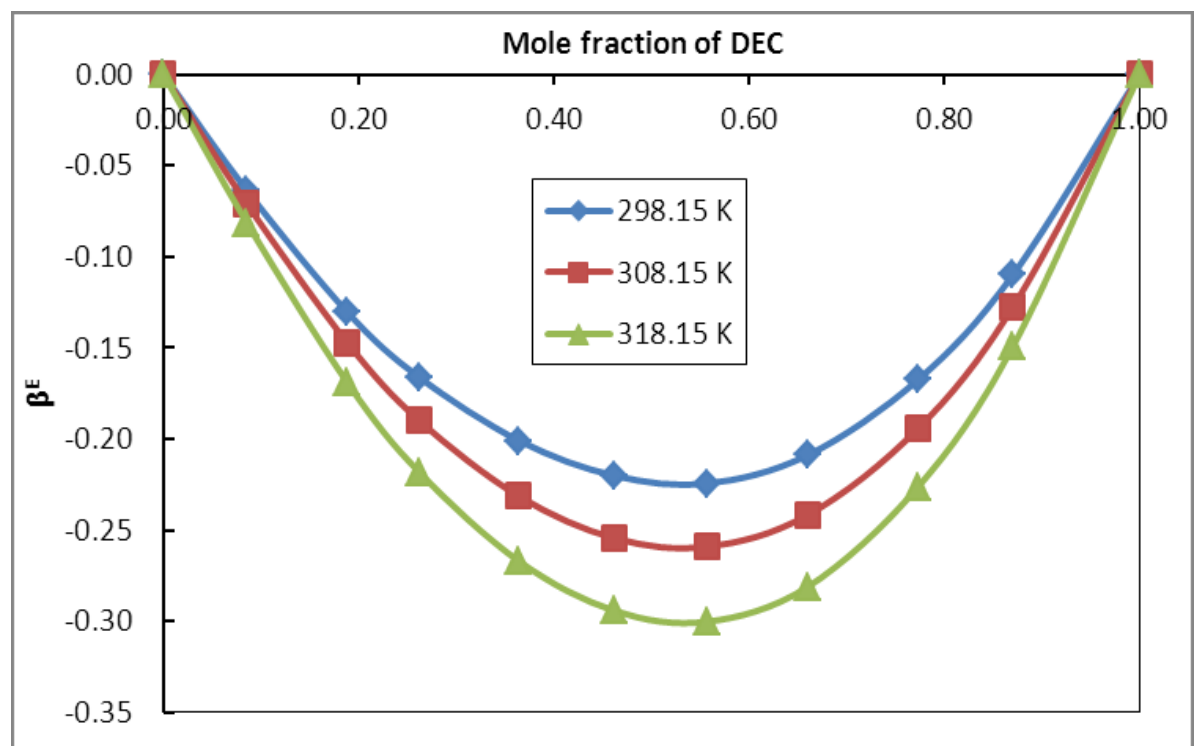

(a)

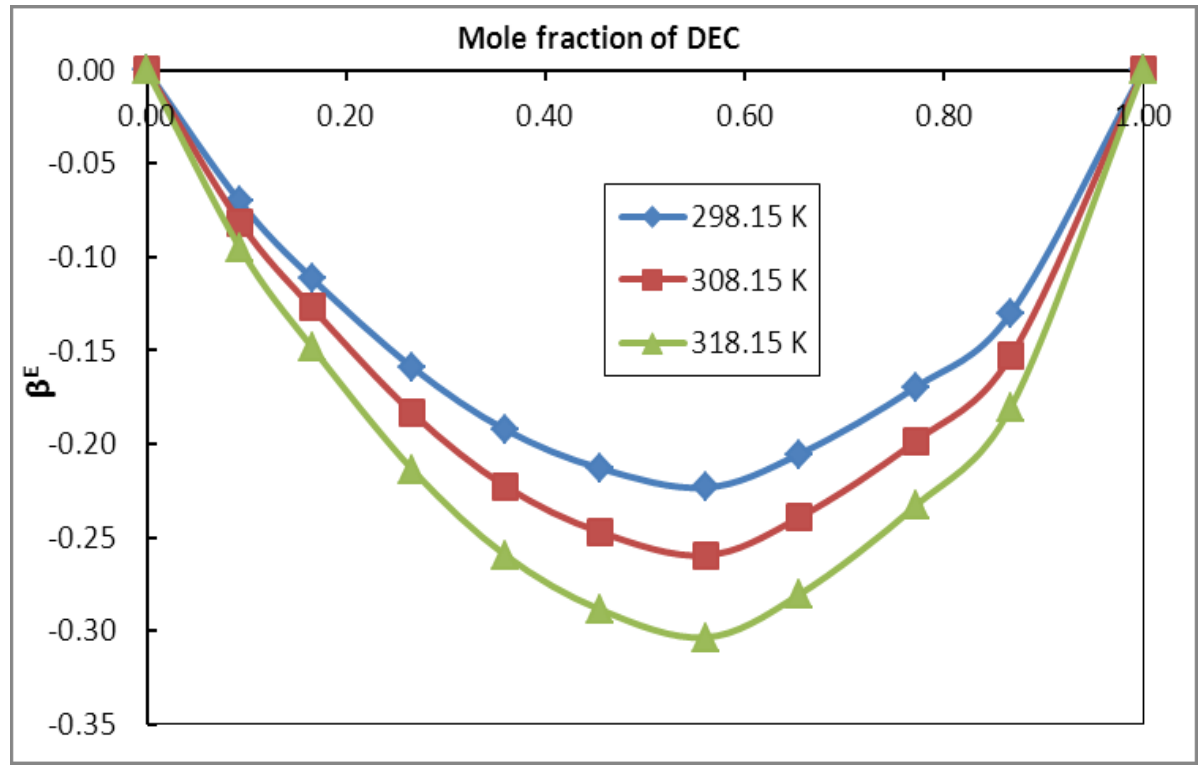

(b)

Figure 1. Variation of Excess Compressibility $\left(\beta^{\mathrm{E}}\right)$ with mole fraction of diethyl carbonate for (a) diethyl carbonate + benzonitrile and (b) diethyl carbonate + benzaldehyde system at different temperatures.

The variation of excess compressibility $\left(\beta^{\mathrm{E}}\right)$, excess free length $\left(\mathrm{L}_{\mathrm{f}}^{\mathrm{E}}\right)$ and excess speed of sound $\left(\mathrm{u}^{\mathrm{E}}\right)$ with mole fraction of diethyl carbonate for the two systems taken up for study at temperatures $298.15,308.15$ and $318.15 \mathrm{~K}$ are shown in Figures $1(\mathrm{a}, \mathrm{b})$ to $3(\mathrm{a}, \mathrm{b})$. The 
variation of excess compressibility $\left(\beta^{\mathrm{E}}\right)$ of the first system with mole fraction of DEC at all temperatures is shown in Figure 1(a). The excess compressibility values are observed to be more negative at mole fraction 0.5563 at all temperatures. Fort et al [11] found that the negative value of excess compressibility's indicates greater interaction between the components of the mixtures. For second system (Figure 1(b)) also, the $\beta^{\mathrm{E}}$ values are observed to be negative.
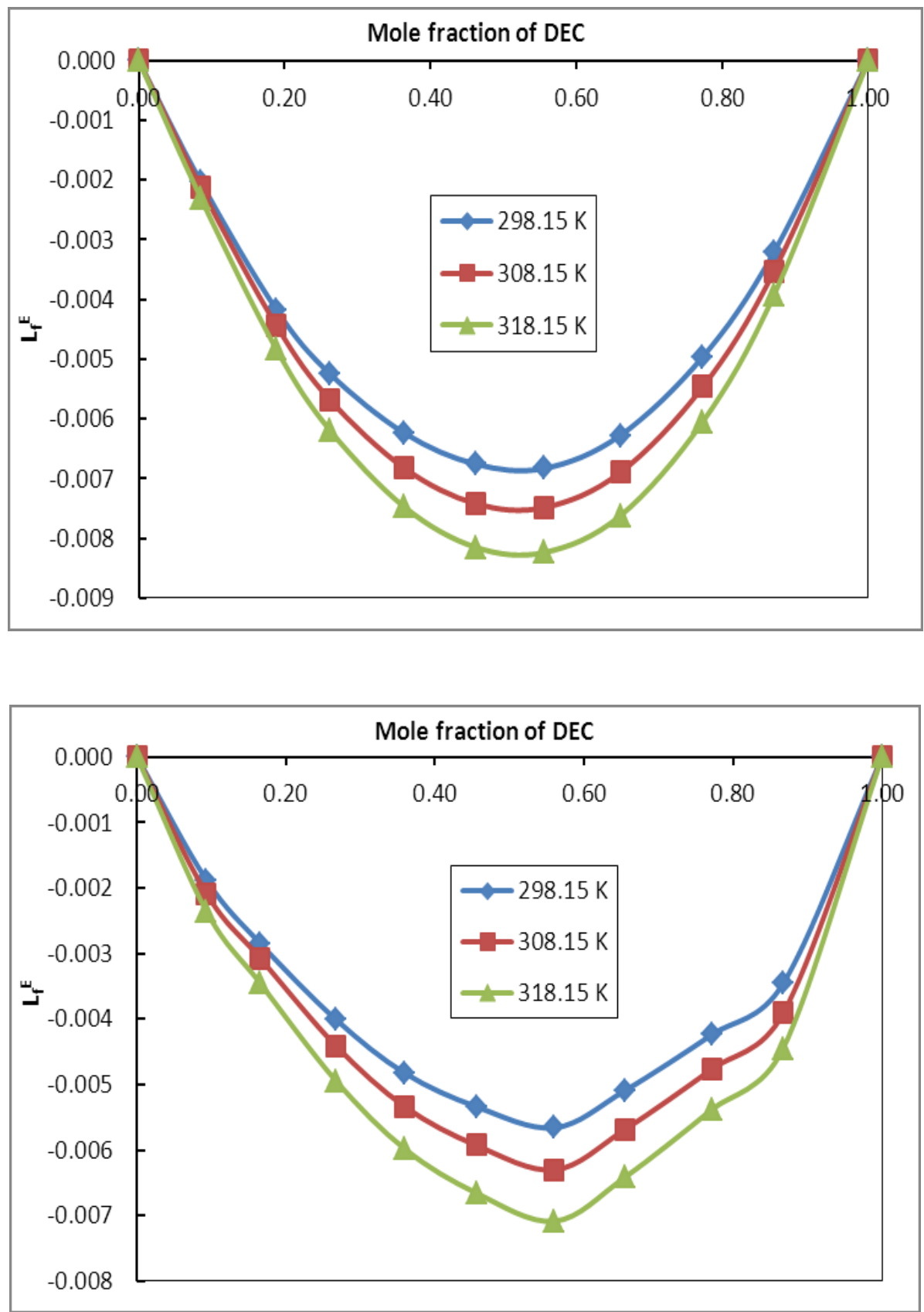

Figure 2. Variation of Excess free length $\left(\mathrm{L}_{\mathrm{F}}^{\mathrm{E}}\right)$ with mole fraction of diethyl carbonate for (a) diethyl carbonate + benzonitrile and (b) diethyl carbonate + benzaldehyde system at different temperatures 
Figure 2(a,b) shows the variation of excess free length with mole fraction of DEC at different temperatures. The excess free length values are observed to be negative for the two systems studies. Similar like observations are noted for all three temperatures. The negative $\mathrm{L}_{\mathrm{f}}^{\mathrm{E}}$ values indicate the presence of strong interactions between unlike molecules. According to Ramamurthy et al [12] negative values of excess intermolecular free length $\mathrm{L}_{\mathrm{f}}^{\mathrm{E}}$ indicate that sound waves cover longer distances due to decrease in intermolecular free length ascribing the dominant nature of hydrogen bond interaction between unlike molecules. Fort et al indicated that the negative excess values are due to charge transfer and hydrogen bond formation.
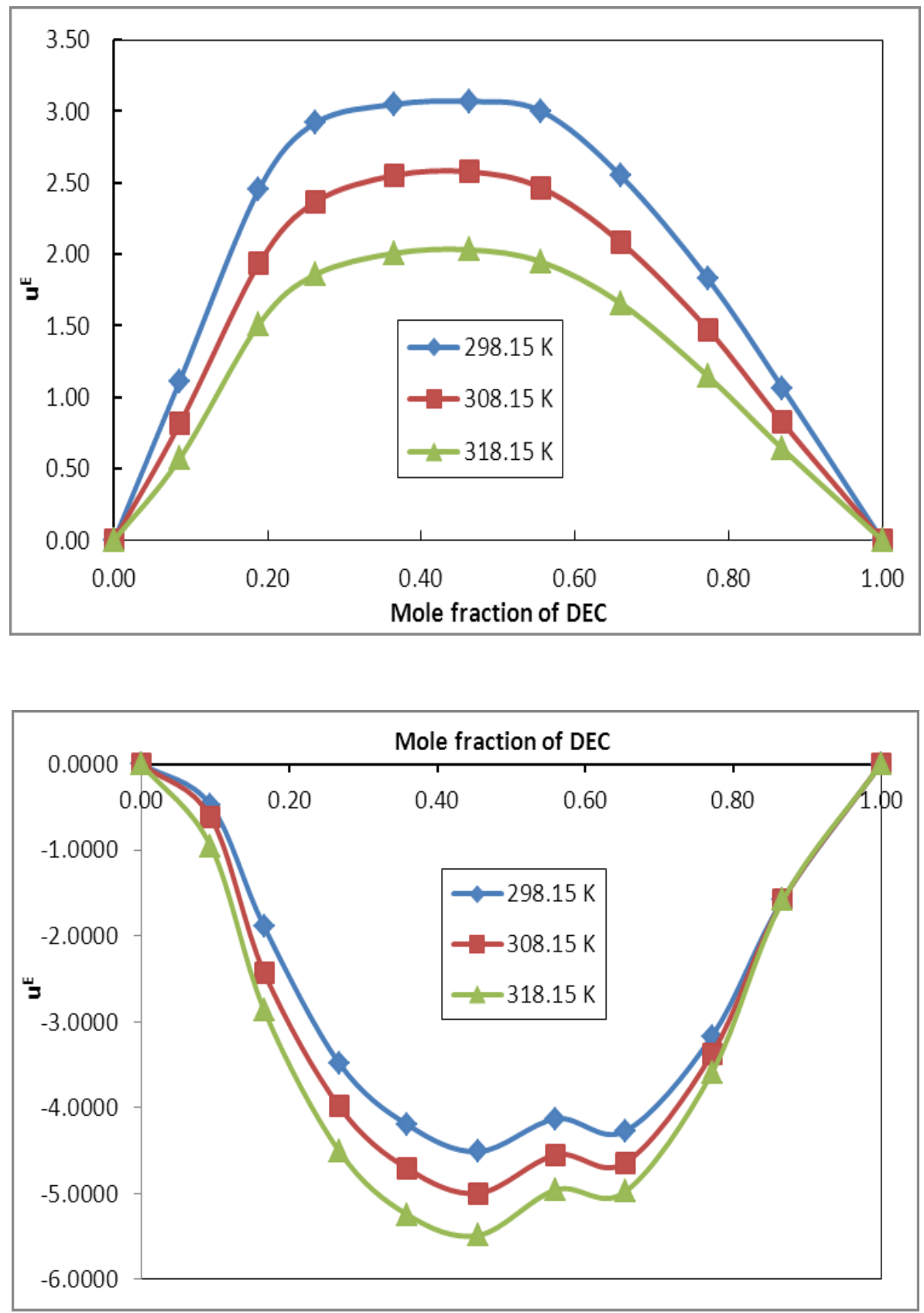

Figure 3. Variation of Excess speed of sound $\left(\mathrm{u}^{\mathrm{E}}\right)$ with mole fraction of diethyl carbonate for (a) diethyl carbonate + benzonitrile and (b) diethyl carbonate + benzaldehyde system at different temperatures. 
Figure 3(a,b) indicates excess speed of sound of binary mixtures with increase in mole fraction of DEC at different temperatures. From Figure 3(a), it is observed that $\mathrm{u}^{\mathrm{E}}$ of the mixture are positive. The $u^{E}$ values are observed to be negative for system 2 (Figure 3(b)). The same trends are observed at all temperatures. The decrease in positive values of $\mathrm{u}^{\mathrm{E}}$ and increase in negative values of $\mathrm{u}^{\mathrm{E}}$ with increase in temperature indicates that the strength of interactions is decreasing with temperature. In diethyl carbonate + benzonitrile system the $\mathrm{uE}$ values are positive. So strong interactions are taking place in diethyl carbonate + benzonitrile mixtures when compared to diethyl carbonate + benzaldehyde mixture.

\section{CONCLUSION}

Experimental values of the speed of sound and density of DEC + benzonitrile, + benzaldehyde mixture have been measured at $298.15 \mathrm{~K}, 308.15 \mathrm{~K}$ and $318.15 \mathrm{~K}$. These data have been used to compute the excess properties of the system. Based on the deviations observed it may be concluded that there are strong interactions between the components of the mixtures.

\section{References}

[1] G.V. Rama Rao, A. Vishwanatha Sarma, D. Ramachandran, C. Rambabu, Indian J. Chem. 46A (2007) 1972.

[2] S. Ravichandran, K. Ramanathan, Journal of Pure and applied ultrasoincs 28 (2006) 40.

[3] A. Mchaweh, A. Alsaygh, M.A. Moshfeghian, Fluid Phase Equilib. 224 (2004) 157-67.

[4] K. Narendra, Ch. Srinivasu, Ch. Kalpana, P. Narayana murthy, J Therm Anal Calorim. 107 (2012) 25-30.

[5] S.S.J. Srinivas, B. Tulasi Koteswari Bai, K. Babu Rao, K. Narendra, M. Sarath babu, International Letters of Chemistry, Physics and Astronomy 10(2) (2013) 33-40.

[6] K. Narendra, Ch. Srinivasu, P. Narayana murthy, J Applied Sciences 12(2) (2012) 136144.

[7] M.V. Ratnam, Sudhir Mohite, M. Nandini, J Mol. Liq. 177 (2013) 229-236.

[8] A. Pal, R.K. Bhardwaj, G. Dass, Int. J Thermophysics 22(3) (2001) 769-87.

[9] P. Subramanyam Naidu, N. Prabhakara Rao, K. Ravindra Prasad, J. Pure and Applied Ultrason. 24 (2002) 36.

[10] G. Arul, L. Palaniappan, Indian J Pure and applied phys. 39 (2001) 561.

[11] R.J. Fort, W.R. Moore, Trans. Faraday Society 61 (1965) 2102.

[12] K. Ramamoorthy, S. Alwan, Current Sci. 47 (1978) 334.

[13] N. Santhi, P. L. Sabarathinam, J. Madhumitha, G. Alamelumangai, M. Emayavaramban, International Letters of Chemistry, Physics and Astronomy 2 (2013) 18-35. 
[14] C. H. Srinivasu, K. Anil Kumar, S. K. Fakruddin, K. Narendra, T. Anjaneyulu, International Letters of Chemistry, Physics and Astronomy 13 (2013) 1-7.

[15] G. Alamelumangai, N. Santhi, International Letters of Chemistry, Physics and Astronomy 5 (2014) 124-133. 